\title{
Pengaruh Economic Value Added, Market Value Added dan Cash Value Added terhadap Return Saham pada Perusahaan Jakarta Islamic Index yang Terdaftar di Bursa Efek Indonesia Tahun 2015-2018
}

\author{
Akuntansi Manajemen \\ Rachel Larasati ${ }^{1)}$, Inayah Adi Sari ${ }^{2)}$, Yanti Puji Astutie ${ }^{3)}$ \\ Fakultas Ekonomi dan Bisnis, Univeritas Pancasakti, Tegal \\ Rlarasati90@gmail.com, inayahadisari@gmail.com, yantie.cc@gmail.com
}

\begin{abstract}
ABSTRACK
The purpose of this study is to examine the effect of Economic Value Added, Market Value Added and Cash Value Added on Stock Returns both simultaneously and partially. The method used in this study is a quantitative research method with a causal descriptive approach. The sample used is the companies included in the Jakarta Islamic Index listed on the Indonesia Stock Exchange in 2015-2018. The number of companies used as samples of this study were 56 companies using purposive sampling method. While the method of data analysis used is descriptive statistical test, classic assumption testing, multiple linear regression analysis, simultaneous significance test ( $F$ test), test the significance of individual parameters ( $t$ test) and coefficient of determination. Based on the results of the study showed Economic Value Added, Market Value Added and Cash Value Added simultaneously had a significant effect on Stock Returns with a significance value of 0.008. While partially, Economic Value Added has a negative and significant effect on Stock Return with a significance value of 0.013, Cash Value Added has a significant effect on Stock Returns with a significance value of 0.009 and Market Value Added partially does not affect Stock Returns with a significance value of 0.124 .
\end{abstract}

Keywords: Economic Value Added, Market Value Added, Cash Value Added and Stock Return

\begin{abstract}
ABSTRAK
Tujuan penelitian ini adalah untuk menguji pengaruh Economic Value Added, Market Value Added dan Cash Value Added terhadap Return Saham baik secara simultan maupun parsial. Metode yang digunakan dalam penelitian ini adalah metode penelitian kuantitatif dengan pendekatan deskriptif kausal. Sampel yang digunakan adalah perusahaan-perusahaan yang masuk dalam Jakarta Islamic Index yang terdaftar di Bursa Efek Indonesia tahun 20152018. Jumlah perusahaan yang dijadikan sampel penelitian ini ada 56 perusahaan dengan menggunakan metode purposive sampling. Sedangkan metode analisis data yang digunakan adalah uji statistik deskriptif, pengujian asumsi klasik, analisis regresi linier berganda, uji signifikansi simultan (uji F), uji signifikansi parameter individual (uji t) dan koefisien determinasi. Berdasarkan hasil penelitian menunjukan Economic Value Added, Market Value Added dan Cash Value Added secara simultan berpengaruh signifikan terhadap Return Saham dengan nilai signifikansi 0,008. Sedangkan secara parsial, Economic Value Added berpengaruh negatif dan signifikan terhadap Return Saham dengan nilai signifikansi 0,013, Cash Value Added berpengaruh signifikan terhadap Return Saham dengan nilai signifikansi 0,009 dan Market Value Added secara parsial tidak berpengaruh terhadap Return Saham dengan nilai signifikansi 0,124.

Kata Kunci : Economic Value Added, Market Value Added, Cash Value Added dan Return Saham
\end{abstract}




\section{Pendahuluan}

Motivasi Penelitian

Penelitian ini dimotivasi yaitu mereplikasi penelitian sebelumnya yang dilakukan Nainggolan, R. R (2016) hanya saja dalam penlitian ini peneliti menambahkan satu variabel yaitu Cash Value Added (CVA).

Latar Belakang

Pasar modal merupakan tempat dimana berbagai instrumen keuangan jangka panjang yang bisa diperjualbelikan. Pasar modal mempunyai peranan penting dalam menunjang perekonomian suatu negara dan merupakan suatu sarana yang dapat dimanfaatkan untuk memobilisasi dana baik dari luar negeri maupun dalam negeri. Sedangkan bagi investor pasar modal merupakan tempat untuk menginvestasikan dananya (Rahayu dan Dana, 2016). Dengan menyertakan modal tersebut, maka seseorang memiliki klaim atas pendapatan perusahaan dan klaim atas aset perusahaan. Oleh karena itu salah satu faktor penting yang menjadi pertimangan investor dalam memilih saham salah satunya yaitu dengan melihat return saham perusahaan (Gendro dan Hadri, 2017:166).

Dalam berinvestasi saham tidak semua perusahaan yang kita pilih dapat menghasilkan return yang tinggi. Return yang tinggi dalam arti dapat memberikan kepuasan kepada investor. Dengan itu investor dituntut untuk cermat dalam memilih perusahaan mana yang akan mereka investasi. Biasanya seorang investor jika akan berinvestasi hal utama yang akan dilihat adalah kinerja keuangan perusahaan. Kinerja keuangan perusahaan dapat dilihat dari laporan keuangan tahun berjalan ataupun tahun sebelumnya (Munawir 2004:2).

Pada umumnya analisis laporan keuangan yang dilakukan perusahaan untuk mengukur kinerja keuangannya adalah dengan metode analisis rasio keuangan. Rasio keuangan dapat dijadikan tolak ukur untuk mengambil keputusan. Tetapi bukan berarti rasio keuangan yang dibuat sudah menjamin $100 \%$ kondisi keuangan yang sesungguhnya (Kasmir, 2010:103). Selain itu analisis laporan keuangan juga memiliki kekurangan atau kelemahan yaitu tidak memperhatikan risiko yang dihadapi perusahaan dengan mengabaikan adanya biaya modal. Untuk mengatasi kekurangan atau kelemahan tersebut, maka dikembangkan konsep pengukuran kinerja keuangan berdasarkan nilai tambah (Value Added) yaitu Economic Value Added (EVA), Market Value Added (MVA) dan Cash Value Added (CVA). Ketiga metode ini dapat dijadikan acuan yang lebih baik bagi pemilik modal untuk mempertimbangkan apakah perusahaan tersebut akan memberikan keuntungan atau kerugian terhadap modal yang diinvestasikan.

Investasi yang sedang berkembang saat ini dan banyak diminati para investor adalah investasi saham berbasis syariah. Karena menganggap investasi tersebut dapat memberikan manfaat dalam menjalankan syariah islam. Salah satu tempat yang menyediakan saham-saham berbasis syariah adalah Jakarta Islamic Index (JII). Walapun terbilang JII terbentuk baru-baru ini tetapi JII selalu menunjukan index saham yang meningkat. Fenomena yang terjadi yakni JII mengalami fluktuasi Return Saham pada tahun 2015 hingga tahun 2018. Pada tahun 2015 menunjukan rata-rata Return Saham sebesar -0,15. Tahun 2016 menunjukan peningkatan rata-rata Return Saham sebesar 0,33. Namun pada tahun 2017 kembali mengalami penurunan Return Saham sebesar 0,02 dan pada tahun 2018 kembali mengalami penurunan sebesar $-0,05$.

Hal tersebut membuktikan bahwa besarnya index saham tidak menjamin semua perusahaan di dalamnya akan memberikan return yang tinggi. Sebagai investor harus tetap jeli dalam memilih perusahaan mana yang akan diinvestasi. Investor yang ingin menginvestasikan pada saham syariah, Jakarta Islamic Index (JII) adalah perusahaan yang tepat untuk berinvestasi karena telah memenuhi unsur-unsur yang telah ditetapkan 
oleh Dewan Syariah Nasional (DSN) dan Majelis Ulama Indonesia (MUI). Perkembangan berbagai usaha di jaman sekarang ini membuat pendekatan Economic Value Added (EVA) Market Value Added (MVA) dan Cash Value Added (CVA) dapat dijadikan salah satu alat pegukur kinerja keuangan yang sangat tepat.

Rumusan Masalah

Berdasarkan latar belakang penelitian yang telah di uraikan di atas, maka perumusan masalah dalam penelitian ini adalah sebagai berikut:

1. Apakah Economic Value Added (EVA), Market Value Added (MVA) dan Cash Valu Added (CVA) berpengaruh secara simultan terhadap Return Saham?

2. Apakah Economic Value Added (EVA) berpengaruh terhadap Return Saham?

3. Apakah Market Value Added (MVA) berpengaruh terhadap Return Saham?

4. Apakah Cash Value Added (CVA) berpengaruh terhadap Return Saham?

Tujuan Penelitian

Berdasarkan perumusan masalah di atas, maka tujuan penelitian ini adalah sebagai berikut:

1. Untuk mengetahui apakah Economic Value Added (EVA), Market Value Added (MVA) dan Cash Value Added (CVA) berpengaruh secara simultan terhadap Return Saham

2. Untuk mengetahui apakah Economic Value Added (EVA) berpengaruh terhadap Return Saham

3. Untuk mengetahui apakah Market Value Added (MVA) berpengaruh terhadap Return Saham

4. Untuk mengetahui apakah Cash Value Added (CVA) berpengaruh terhadap Return Saham

\section{Kerangka Pemikiran dan Hipotesis}

2.1 Kerangka Pemikiran

Adapun kerangka pemikiran dalam penelitian ini sebagai berikut :

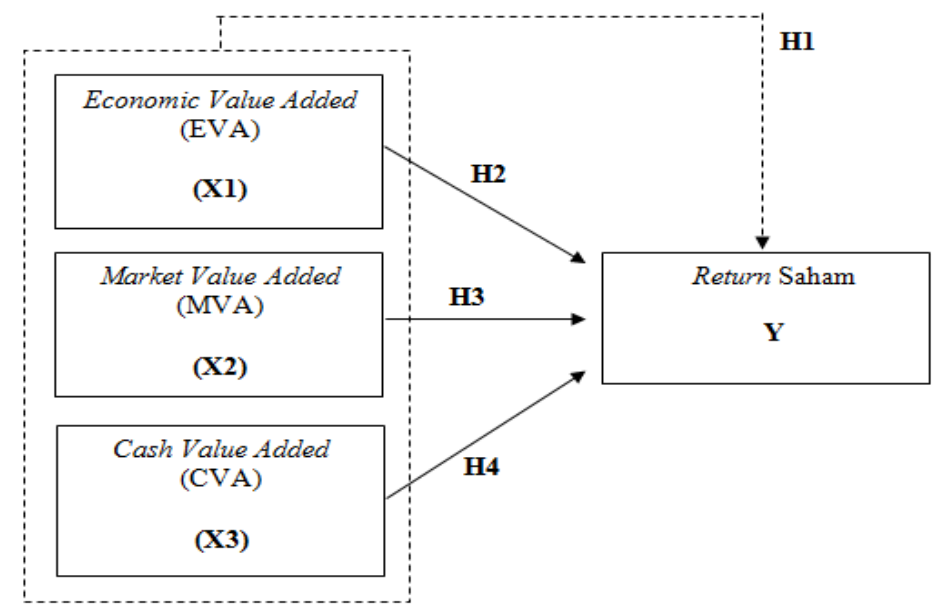

Gambar 2.1

Kerangka Pemikiran Penelitian 


\subsection{Hipotesis}

Dari permasalahan dan kerangka konseptual yang telah dikemukakan diatas, maka hipotesis dalam penelitian ini dapat dirumuskan sebagai berikut:

H1: Economic Value Added (EVA), Market Value Added (MVA) dan Cash Value Added (CVA) berpengaruh secara simultan terhadap Return Saham

H2: Economic Value Added (EVA) berpengaruh terhadap Return Saham

H3: $\quad$ Market Value Added (MVA) berpengaruh terhadap Return Saham

H4: $\quad$ Cash Value Added (CVA) berpengaruh terhadap Return Saham

\section{Metode Penelitian}

Metode yang digunakan dalam penelitian ini adalah metode penelitian kuantitatif dengan pendekatan deskriptif kausal. Pengambilan sampel dalam penelitian ini meliputi perusahaan-perusahaan yang masuk dalam Jakarta Islamic Index (JII) yang terdaftar di Bursa Efek Indonesia (go public) tahun 2015-2018. Sedangkan teknik yang digunakan dalam penelitian ini menggunakan cara purposive sampling. Variabel yang digunakan dalam penelitian ini adalah variabel terikat (dependent) yaitu Return Saham dan variabel bebas (independent) yaitu Economic Value Added (EVA), Market Value Added (MVA) dan Cash Value Added (CVA).

Teknik analisis data yang digunakan pada penelitian ini adalah Analisis Regresi Berganda. Teknik ini digunakan untuk menjelaskan hubungan antara variabel-variabel independen dengan variabel dependen secara parsial atau simultan.

\section{Hasil}

Berdasarkan hasil data yang dikumpulkan dengan metode pengumpulan data peroleh deskripsi data tentang variabel penelitian seperti pada tabel berikut:

\subsection{Statistik Deskriptif}

Descriptive Statistics

\begin{tabular}{|l|r|r|r|r|r|}
\hline & N & Minimum & Maximum & Mean & Std. Deviation \\
\hline EVA (X1) & 52 & $-201901,00$ & 26848935,00 & 4324174,212 & 5597890,1850 \\
& & & & 0 & 0 \\
\hline MVA (X2) & 52 & 8520246631, & 42651182660 & 88854386640 & 10736453920 \\
& & 00 & 0,00 &, 0000 & 0,00000 \\
\hline CVA (X3) & 52 & $-7773057,00$ & 25772681,00 & 4206102,769 & 6770222,1570 \\
& & & & 0 & 0 \\
\hline $\begin{array}{l}\text { Return Saham } \\
\text { (Y) }\end{array}$ & 52 &,- 39 &, 53 &,- 0094 &, 21296 \\
\hline $\begin{array}{l}\text { Valid N } \\
\text { (listwise) }\end{array}$ & 52 & & & & \\
\hline
\end{tabular}

Sumber: data diolah dengan SPSS

Variabel Economic Value Added (EVA) memiliki nilai rata-rata (mean) sebesar 4324174,2120 dan standar deviasi sebesar 5597890,18500. Variabel Market Value Added (MVA) memiliki nilai rata-rata (mean) sebesar 88854386640,0000 dan standar deviasi sebesar 107364539200,00000. Variabel Cash Value Added (CVA) memiliki nilai rata-rata (mean) sebesar 4206102,7690 dan standar deviasi sebesar 6770222,15700. Variabel Return Saham (Y) memiliki nilai rata-rata (mean) sebesar 0,0094 dan standar deviasi sebesar 0,21296. 
4.2 Uji Normalitas

One-Sample Kolmogorov-Smirnov Test

\begin{tabular}{|l|l|r|}
\hline \multicolumn{2}{|l|}{} & $\begin{array}{c}\text { Unstandardiz } \\
\text { ed Residual }\end{array}$ \\
\hline $\mathrm{N}$ & Mean & 52 \\
\hline Normal Parameters & a,b &, 0000000 \\
\cline { 2 - 3 } & $\begin{array}{l}\text { Std. } \\
\text { Deviation }\end{array}$ &, 18862837 \\
\hline \multirow{2}{*}{ Most Extreme Differences } & Absolute &, 096 \\
\cline { 2 - 3 } & Positive &, 096 \\
\cline { 2 - 3 } & Negative &,- 053 \\
\hline \multicolumn{2}{|l|}{ Test Statistic } &, 096 \\
\hline Asymp. Sig. (2-tailed) &, $200^{\mathrm{c}, \mathrm{d}}$ \\
\hline
\end{tabular}

a. Test distribution is Normal.

b. Calculated from data.

Sumber: data diolah dengan SPSS

besarnya nilai uji Kolmogorov-Smirnov (K-S) adalah 0,096 dan nilai Asymp. Sig. (2-tailed) sebesar 0,200 lebih besar dari 0,05. Hal ini menunjukan data residual sudah terdistribusi secara normal dan model regresi layak dipakai untuk penelitian.

\subsection{Uji Multikolonieritas}

\begin{tabular}{|c|c|c|c|}
\hline & \multicolumn{2}{|c|}{ Coefficients $^{\mathrm{a}}$} \\
\hline & & \multicolumn{2}{|c|}{ Collinearity Statistics } \\
\hline \multicolumn{2}{|c|}{ Model } & Tolerance & VIF \\
\hline \multirow[t]{4}{*}{1} & (Constant) & & \\
\hline & EVA $(X 1)$ &, 073 & 13,684 \\
\hline & $\operatorname{MVA}(\mathrm{X} 2)$ & ,307 & 3,258 \\
\hline & CVA (X3) & ,082 & 12,200 \\
\hline
\end{tabular}

Sumber: data diolah dengan SPSS

Hasil uji Multikolinieritas belum memenuhi syarat untuk dilanjutkan, dapat dilihat dari nilai Tolerance pada variabel EVA sebesar 0,073 dan CVA sebesar 0,82 lebih kecil dari 0,10. Dan nilai VIF pada variabel EVA sebesar 13,684 dan CVA sebesar 12,200 lebih besar dari 10. Hal ini menunjukan bahwa data tersebut belum layak dipakai untuk penelitian. Sehingga untuk memperbaiki agar data tersebut layak, maka perlu mengurangi sampel perusahaan PT. Telekomunikasi Indonesia Tbk dari tahun 2015-2018. Dan jumlah sampel yang digunakan menjadi 52 perusahaan. Berikut hasil uji Multikolonieritas setelah mengeluarkan data perusahaan PT. Telekomunikasi Indonesia Tbk dari tahun 2015-2018 :

Coefficients $^{\mathrm{a}}$

\begin{tabular}{|c|c|c|c|}
\hline \multirow{2}{*}{\multicolumn{2}{|c|}{ Model }} & \multicolumn{2}{|c|}{ Collinearity Statistics } \\
\hline & & Tolerance & VIF \\
\hline \multirow[t]{4}{*}{1} & (Constant) & & \\
\hline & EVA (X1) & ,134 & 7,439 \\
\hline & MVA (X2) & ,449 & 2,226 \\
\hline & CVA (X3) & , 141 & 7,108 \\
\hline
\end{tabular}

Sumber: data diolah dengan SPSS 
hasil pengujian Multikolonieritas setelah mengurangi sampel perusahaan PT. Telekomunikasi Indonesia Tbk dari tahun 2015-2018, menunjukan nilai Tolerance dan VIF telah terdistribusi secara normal dan data layak dipakai untuk penelitian.

\subsection{Uji Autokorelasi}

\begin{tabular}{|c|c|c|c|c|c|}
\hline \multicolumn{6}{|c|}{ odel Summaryb } \\
\hline Model & $\mathrm{R}$ & R Square & $\begin{array}{l}\text { Adjusted R } \\
\text { Square }\end{array}$ & $\begin{array}{l}\text { Std. Error of } \\
\text { the Estimate }\end{array}$ & $\begin{array}{l}\text { Durbin- } \\
\text { Watson }\end{array}$ \\
\hline 1 &, $464^{\mathrm{a}}$ & ,215 & , 166 & ,19443 & 2,157 \\
\hline
\end{tabular}

a. Predictors: (Constant), CVA (X3), MVA (X2), EVA (X1)

b. b. Dependent Variable: RETURN SAHAM (Y)

Sumber: data diolah dengan SPSS

Berdasarkan tabel di atas menunjukan nilai Durbin-Watson sebesar 2,157. Nilai tersebut kemudian dilakukan pengambilan keputusan dengan ketentuan du < $\mathrm{d}<4$-du $(1,6769<2,157<2,3231)$. Hal ini dapat disimpulkan bahwa tidak terjadi Autokorelasi antar variabel independen dan penelitian dapat dilanjutkan dengan model regresi.

\subsection{Uji Heterokedastisitas}

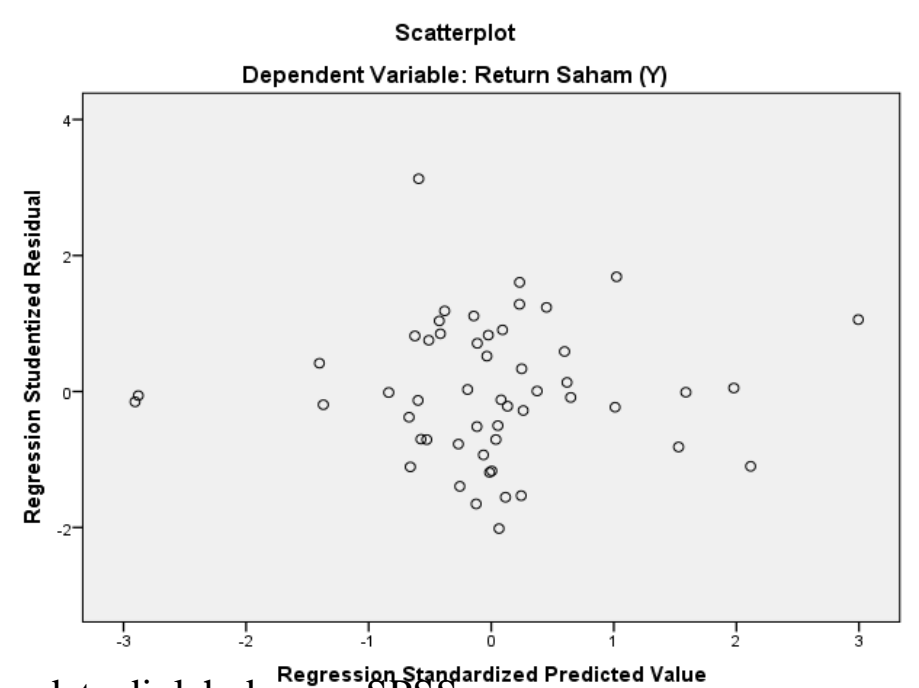

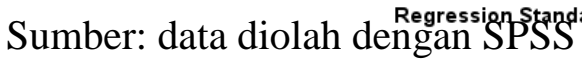

Dari hasil grafik Scatterplot terlihat bahwa adanya titik-titik menyebar membentuk pola yang tidak jelas atau titik-titik tidak membentuk pola tertentu serta penyebaran titiktitik tersebut berada di atas dan di bawah akya 0 dan sumbu Y. Dengan demikian dapat disimpulkan bahwa model persamaan regresi tidak terjadi gejala Heterokedastisitas.

\subsection{Uji Analisis Regresi Linier Berganda}

\begin{tabular}{|l|l|r|r|r|}
\hline \multirow{4}{*}{ Model } & & \multicolumn{2}{|c|}{ Unstadardized Coefficients } & \multicolumn{1}{c|}{$\begin{array}{c}\text { Stadardized } \\
\text { Coefficients }\end{array}$} \\
\cline { 3 - 5 } 1 & & \multicolumn{1}{|c|}{ B } & Std. Error & \multicolumn{1}{c|}{ Beta } \\
\cline { 3 - 5 } & (Constant) &,- 036 &, 037 &,- 904 \\
\cline { 2 - 5 } & EVA (X1) & $-, 3,438 \mathrm{E}-8$ &, 000 &, 299 \\
\cline { 2 - 5 } & MVA (X2) & $5,928 \mathrm{E}-13$ &, 000 &, 924 \\
\cline { 2 - 5 } & CVA (X3) & $2,905 \mathrm{E}-8$ &, 000 & \\
\hline
\end{tabular}


a. Dependent Variabel: Return Saham (Y)

Sumber: data diolah dengan SPSS

Berdasarkan hasil analisis regresi berganda diperoleh persamaan sebagai berikut :

$\mathrm{Y}=-0,036-0,00000003438 \mathrm{X} 1+0,0000000000005928 \mathrm{X} 2+0,000000002905 \mathrm{X} 3$ $+\varepsilon$

Tabel 4.8 menunjukan prediksi masing-masing variabel. Dari persamaan regresi berganda di atas dapat diambil kesimpulan sebagai berikut :

1. Konstanta sebesar -0,036, hal ini berarti apabila nilai variabel independen Economic Value Added (EVA), Market Value Added (MVA), dan Cash Value Added (CVA) bernilai 0, maka variabel dependen yaitu Return Saham akan memiliki nilai sebesar -0,036 persen.

2. Koefisien regresi variabel Economic Value Added (X1) sebesar 0,00000003438 dengan arah negatif. Artinya jika variabel Economic Value Added (EVA) terjadi penurunan sedangkan variabel lain tetap, maka akan menurunkan Return Saham sebesar -0,00000003438 persen.

3. Koefisien regresi variabel Market Value Added (X2) sebesar 0,0000000000005928 dengan arah koefisien positif. Artinya jika variabel Market Value Added ditingkatkan sedangkan variabel lain tetap, maka akan meningkatkan Return Saham sebesar 0,0000000000005928 persen.

4 Koefisien regresi variabel Cash Value Added (X3) sebesar 0,000000002905 dengan arah koefisien positif. Artinya jika variabel Cash Value Added ditingkatkan sedangkan variabel lain tetap, maka akan meningkatkan Return Saham sebesar 0,000000002905 persen.

\subsection{Uji Koefisien Determinasi}

\section{Model Summary ${ }^{b}$}

\begin{tabular}{|l|l|r|r|r|}
\hline Model & R & R Square & $\begin{array}{c}\text { Adjusted R } \\
\text { Square }\end{array}$ & $\begin{array}{c}\text { Std. Error of } \\
\text { the Estimate }\end{array}$ \\
\hline 1 &, $464^{\mathrm{a}}$ &, 215 &, 166 &, 19443 \\
\hline
\end{tabular}

a. Predictors: (Constant), CVA (X3), MVA (X2), EVA (X1)

b. Dependent Variable: Return Saham (Y)

Sumber: data diolah dengan SPSS

Berdasarkan hasil dari tabel dapat dilihat nilai R Square sebesar 0,166 yang berarti sebesar 16,6\% variasi variabel dependen (Return Saham) yang dapat dijelaskan oleh variabel independen (Economic Value Added, Market Value Added, dan Cash Value Added). Sedangkan sisanya 83,4\% dijelaskan oleh variabel lain diluar model penelitian ini. 


\subsection{Uji Signifikansi Simultan}

\begin{tabular}{|c|c|c|c|c|c|c|}
\hline \multicolumn{7}{|c|}{ ANOVA $^{\mathrm{a}}$} \\
\hline \multicolumn{2}{|c|}{ Model } & $\begin{array}{l}\text { Sum of } \\
\text { Squares }\end{array}$ & Df & Mean Square & $\mathrm{F}$ & Sig. \\
\hline \multirow[t]{3}{*}{1} & Regression &, 498 & 3 & ,166 & 4,393 &, $008^{b}$ \\
\hline & Residual & 1,815 & 48 & ,038 & & \\
\hline & Total & 2,313 & 51 & & & \\
\hline
\end{tabular}

a. Dependent Variable: Return Saham (Y)

b. Predictors: (Constant). CVA (X3), MVA (X2), EVA (X1)

Sumber: data diolah dengan SPSS

Berdasarkan tabel hasil uji simultan (F-test) di atas dapat disimpulkan bahwa nilai signifikansi 0,008 lebih kecil dari $0,05(0,008<0,05)$. Hal ini menunjukan bahwa variabel Economic Value Added, Market Value Added, dan Cash Value Added secara bersama-sama (simultan) berpengaruh signifikan terhadap Return Saham. Maka hipoteisi diterima.

\subsection{Uji Signifikan Parameter}

\begin{tabular}{|c|l|r|r|r|r|}
\hline Model & & \multicolumn{3}{|c|}{$\begin{array}{c}\text { Unstadardized } \\
\text { Coefficients }\end{array}$} & \\
\cline { 3 - 6 } 1 & & \multicolumn{1}{|c|}{ B } & Std. Error & \multicolumn{1}{c|}{ T } & \multicolumn{1}{c|}{ Sig. } \\
\cline { 3 - 6 } & &,- 036 &, 037 &,- 971 &, 337 \\
\cline { 3 - 6 } & (Constant) & $-3,438 \mathrm{E}-8$ &, 000 & $-2,592$ &, 013 \\
\cline { 2 - 6 } & EVA (X1) & $5,928 \mathrm{E}-$ &, 000 & 1,567 &, 124 \\
\cline { 2 - 6 } & MVA (X2) & 13 & & &, 009 \\
\cline { 2 - 6 } & CVA (X3) & $2,905 \mathrm{E}-8$ &, 000 & 2,710 & \\
\cline { 2 - 6 } & & & & \\
\hline
\end{tabular}

Dependent Variabel: Return Saham $(Y)$

Sumber: data diolah dengan SPSS

Tabel diatas, menerangkan bahwa hasil uji t sebagai berikut:

1. Economic Value Added (X1)

Dari perhitungan uji t menggunakan SPSS versi 24, nilai koefisien regresi sebesar $-0,00000003438$ dengan tingkat signifikansi $0,013<0,05$, maka hipotesis diterima. Sehingga dapat disimpulkan bahwa Economic Value Added secara parsial berpengaruh negatif sebesar -0,00000003438 dan signifikan sebesar 0,013 terhadap Return Saham pada perusahaan Jakarta Islamic Index yang terdaftar di Bursa Efek Indonesia.

2. Market Value Added (X2)

Dari perhitungan uji t menggunakan SPSS versi 24, nilai koefisien regresi sebesar 0,0000000000005928 dengan tingkat signifikansi 0,124 >0,05, maka hipotesis ditolak. Sehingga dapat disimpulkan bahwa Economic Value Added secara parsial tidak berpengaruh terhadap Return Saham pada perusahaan Jakarta Islamic Index yang terdaftar di Bursa Efek Indonesia.

3. Cash Value Added (X3)

Dari perhitungan uji t menggunakan SPSS versi 24, nilai koefisien regresi sebesar 0,00000002905 dengan tingkat signifikansi 0,009 < 0,05, maka hipotesis 
diterima. Sehingga dapat disimpulkan bahwa Economic Value Added secara parsial berpengaruh positif sebesar 0,00000002905 dan signifikan sebesar 0,009 terhadap Return Saham pada perusahaan Jakarta Islamic Index yang terdaftar di Bursa Efek Indonesia.

\section{Kesimpulan dan Saran}

\section{A. Kesimpulan}

Berdasarkan analisis dan pembahasan yang telah dilakukan dalam penelitian ini dapat disimpulkan bahwa :

1. Economic Value Added (EVA), Market Value Added (MVA) dan Cash Value Added (CVA) secara simultan berpengaruh terhadap Return Saham pada perusahaan Jakarta Islamic Index (JII) yang terdaftar di Bursa Efek Indonesia (BEI) tahun 2015-2018. Sehingga hipotesis diterima.

2. Economic Value Added (EVA) secara parsial berpengaruh terhadap Return Saham pada perusahaan Jakarta Islamic Index (JII) yang terdaftar di Bursa Efek Indonesia (BEI) tahun 2015-2018. Sehingga hipotesis diterima.

3. Market Value Added (MVA) secara parsial tidak berpengaruh terhadap Return Saham pada perusahaan Jakarta Islamic Index (JII) yang terdaftar di Bursa Efek Indonesia (BEI) tahun 2015-2018. Sehingga hipotesis ditolak.

4. Cash Value Added (CVA ) secara parsial berpengaruh terhadap Return Saham pada perusahaan Jakarta Islamic Index (JII) yang terdaftar di Bursa Efek Indonesia (BEI) tahun 2015-2018. Sehingga hipotesis di terima.

\section{B. Saran}

Penelitian lanjutan menjadi suatu hal penting dalam rangka mendukung perkembangan Return Saham di Indonesia. Berdasarkan hasil penelitian yang telah dilakukan ada beberapa saran yang dapat diajukan. Saran-saran yang dapat disampaikan adalah sebagai berikut :

1. Economic Value Added (EVA), Market Value Added (MVA) dan Cash Value Added (CVA) berpengaruh terhadap Return Saham. Oleh karena itu seorang investor yang akan menginvestasikan sahamnya diharapkan variabel tersebut dapat dijadikan acuan yang lebih baik dalam mempertimbangkan Return Saham.

2. Economic Value Added (EVA) berpengaruh terhadap Return Saham. Oleh karena itu perusahaan diharapkan dapat mempertahankan atau meningkatkan laba perusahaan agar investor semakin tertarik untuk menginvestasikan saham pada perusahaan tersebut.

3. Market Value Added (MVA) tidak berpengaruh terhadap Return Saham. Dengan demikian investor dalam berinvestasi harus lebih teliti dan jeli dalam memilih perusahaan mana yang akan mereka investasikan dengan melihat analisis teknikal di setiap perusahaan.

4. Cash Value Added (CVA) berpengaruh terhadap Return Saham. Oleh karena itu perusahaan diharapkan lebih memperhatikan perputaran kas agar menghasilkan kas lebih optimal lagi. Sehingga investor akan semakin tertarik untuk menginvestasikan saham pada perusahaan tersebut.

5. Untuk penelitian selanjutnya diharapkan dapat memperluas penelitian variabel-variabel lain seperti EPS, ROI, ROCE, ROE dan sebagainya, sehingga dapat meningkatkan kemampuan menjelaskan variabel dependen (Return Saham) dan meningkatkan akurasi hasil penelitian yang diperoleh. 


\section{DAFTAR PUSTAKA}

Alexander, N \& Destriana, N. (2013). Pengaruh Kinerja Keuangan Terhadap Return Saham. Jurnal Bisnis dan Akuntansi Vol. 15 No. 2:123-132

Arnova, I. (2016). Pengaruh Ukuran Kinerja ROA, ROE, EPS dan EVA Terhadap Return Saham. Ekombis Review, 4(1).

Athur, A. G. (1970). The Market For "Lemons: Quality Uncertainty and The Market Mechanism”. The Quarterly Journal of Economic, 84 (3): 499-500.

Baridwan, Z. (2004). Accounting Intermediate. Edisi Kedelapan, Cetakan Pertama. Penerbit BPFE Universitas Gadjah Mada. Yogyakarta.

Brigham, E. F., \& Houston, J. F. (2001). Manajemen Keuangan. Buku 1 edisi 8. Jakarta: Erlangga.

Conelly et al. (2011). "Signaling Theory : A Review and Assessment". Journal of Management, Januari Vol. 37 No.1.

Erasmus, P. (2008). The relative and incremental information content of the value-based financial performance measure Cash Value Added (CVA). Management Dynamics: Journal of the Southern African Institute for Management Scientists, 17(1), 2-15.

Fanani, Z. (2009). Kualitas Pelaporan Keuangan. Jurnal Akuntansi \& Keuangan Indonesia Vol. 6 No. 1:21-36.

Fountaine, D., Jordan, D. J., \& Phillips, G. M. (2008). Using economic value added as a portfolio separation criterion. Quarterly Journal of Finance and Accounting, 69-81.

Ghozali, I. (2018). Aplikasi Analisis Multivariate dengan program IBM SPSS 25 Edisi 9. Semarang: Badan Penerbit Universitas Diponegoro.

Hejazi, R \& Oskouei, M. (2007). The Information Content Of CVA And P/E Ratio : Evidence On Association With Stock Returns Of Industrial Companies In The Tehran Stock Exchange Iranian. ACC \& Auditing Review, 14 (47):21-36.

Hendriarsanto, P. (2005). Analisis pengaruh Market Value Added, DER, Trading Day dan Trading Volume terhadap Return Saham. Skripsi. UNDIP.

Isti, C. \& Rahyuda. (2016). Pengaruh DER, ROA, PER dan EVA terhadap Return Saham. E-Jurnal Manajemen Unud Vol. 5 No. 3.

Jama'an. (2008). Pengaruh Mekanisme Corporate Governance Terhadap Integritas Informasi Laporan Keuangan. Semarang: UNDIP.

Jogiyanto, H. (2003). Teori Portofolio Dan Analisis Investasi Edisi Ketiga, Yogyakarta. BPFE USM.

Kristiana. V. A \& Sriwidodo. (2011). Analisis Faktor-faktor yang Mempengaruhi Return Saham pada Perusahaan Manufatur Tahun 2007-2009 yang terdaftar di Bursa Efek Indonesia. Jurnal Manajemen Unud Vol. 7 No. 1.

Mamduh, H. (2008). Manajemen Keuangan Edisi 1. Yogyakarta: BPFE.

Marsiwi. D. (2013). Pengaruh Cash Value Added (CVA) dan Earning Share Ratio 
terhadap Return Saham. Jurnal Ekuilibrium Vol. 11 No. 2.

Nainggolan, R. R. (2016). Analisis Pengaruh Return On Assets, Economic Value Added dan Market Value Added terhadap return Saham. Jurnal Riset Bisnis \& Manajemen Vol. 3 No. 2.

Pradhono \& Setiawan, Y. J. (2004). Pengaruh EVA, Residual Income, Earning dan Arus Kas Operasi Terhadap Return Yang diterima oleh Pemegang Saham. Jurnal Akuntansi dan Keuangan, 6, 140-163.

Rahayu \& Dana, I. M. (2016). Pengaruh EVA, MVA dan Likuiditas Terhadap Harga Saham Pada Peusahaan Food And Beverages. E-Jurnal Manajemen Unud. Vol. 5(1):443-469.

Rahmadi, Y. D. (2013). Pengaruh Earning Per Share, Arus Kas Operasi, Economic Value Added, dan Market Value Added Terhadap Return Saham (Studi pada Perusahaan Manufaktur yang Terdaftar pada BEI). Jurnal Akuntansi, 1(3).

Sartono, A. (2001). Manajemen Keuangan teori dan Aplikasi Edisi 4. Yogyakarta: BPFE.

Sekaran, U. (2006). Metodologi Penelitian Untuk Bisnis. Jakarta: Salemba Empat. Sekaran, U. (2011). Metodologi Penelitian Untuk Bisnis. Jakarta: Salemba Empat. Senohadi, V. S. \& Pangeran. (2014). Pengaruh Nilai Buku, Economic Value Added dan Return On Asset terhadap Return Saham. Jurnal JRMB Vol.9 No. 2.

Sudana, I. M. (2015). Manajemen Keuangan Perusahaan Edisi 2, Jakarta. Erlangga.

Sugara, O. B \& Fakhrudin. (2016). Pengaruh Economic Value Added, Market Value Added, Cash Value Added, terhadap Return Saham. Jurnal Akuntansi Vol. 6 No. 1.

Suwarjono. (2010). Teori Akuntansi. Pengungkapan dan Sarana Interprelatif Edisi Ketiga. Yogyakarta: BPFE

Warsono. (2003). Manajemen Keuangan Perusahaan Edisi Ketiga, Jilid 1. Malang: Bayumedia Publising.

Widagdo. B \& Suryani. (2009). Kinerja Beberapa Perusahaan Sektor Pertambangan yang Sahamnya Tercatat di Bursa Efek Indonesia (BEI). Jurnal Ekonomi Sumber Daya. Vol. 10 No. 1.

Wiyono, G., \& Kusuma, H. (2017). Manajemen Keuangan Lanjutan Berbasis Corporate Value Creation. Yogyakarta: UPP STIM YKPN.

Young, S. d. (2001). Penilaian Kinerja Keuangan Perusahaan dengan Menggunakan Metode Market Value Added (MVA). Jakarta: Salemba Empat.

Yubardini. (2005). Perbandingan Penggunaan Metode Economic Value Added dan Cash Value Added dalam menilai Kinerja Keuangan Perusahaan. Jurnal Akuntansi tahun 1x/02 PP 220-231 